\title{
Anticorpos Antiproteínas Citrulinadas e a Artrite Reumatóide
}

\section{Auto-Antibodies to Citrullinated Proteins and Rheumatoid Arthritis}

\author{
Renata Trigueirinho Alarcon ${ }^{(1)}$, Luís Eduardo Coelho Andrade ${ }^{(2)}$
}

\section{RESUMO}

Pacientes com artrite reumatóide (AR) possuem uma variedade de auto-anticorpos no soro e no líquido sinovial. Entre esses autoanticorpos, destacam-se aqueles direcionados a proteínas citrulinadas, que são específicos para AR, aparecem precocemente durante a evolução da enfermidade e são bastante úteis para auxiliar no diagnóstico da doença. Entre os antígenos citrulinados reconhecidos por auto-anticorpos na $\mathrm{AR}$, encontram-se a profilagrina, a filagrina e a vimentina. Células e tecidos ricos nessas proteínas serviram de substrato para os primeiros ensaios laboratoriais para detecção dessa classe de auto-anticorpos. A descoberta de que os epitopos reconhecidos por esses auto-anticorpos eram peptídeos contendo citrulina permitiu o desenvolvimento de uma plataforma baseada em ELISA. O formato de ELISA possibilitou maior padronização e reprodutibilidade dos ensaios, resultando em ampla aceitação mundial como os auto-anticorpos mais específicos e precoces para o diagnóstico da AR. Há controvérsia quanto à capacidade dos anticorpos contra proteínas citrulinadas predizerem a gravidade da doença. O papel dos antígenos citrulinados na fisiopatologia da artrite reumatóide é sugerido pela forte especificidade desses auto-anticorpos para a doença, pelo achado de proteínas citrulinadas na sinóvia inflamada, pela produção intra-articular desses auto-anticorpos e pela extrema afinidade de peptídeos citrulinados por moléculas de HLA-DRBI que contêm o epitopo compartilhado. Esses achados acenam com a possibilidade de novas e fascinantes descobertas rumo à melhor compreensão da fisiopatologia da AR.

Palavras-chaves: atrite reumatóide, citrulina, anticorpo antiproteínas citrulinadas, auto-anticorpos.

\section{INTRODUÇÃO}

Os auto-anticorpos são imunoglobulinas (Ig) que reagem contra antígenos próprios de tecido autólogo. Mesmo sendo relacionados a uma variedade de doenças auto-imunes, eles podem constituir uma resposta fisiológica normal $^{(1)}$. De fato, indivíduos normais podem apresentar, ainda que em baixas concentrações, imunoglobulinas circulantes capazes de se ligarem a uma variedade de auto-

\begin{abstract}
Rheumatoid arthritis $(R A)$ patients have a variety of auto-antibodies in the serum and synovial fluid. Among these auto-antibodies, those directed against citrullinated proteins are distinguished because that are specific for $R A$, appear early during the evolution of the disease and they are important to assist in the diagnosis of the illness. Examples of citrullinated antigens recognized by autoantibodies in rheumatoid arthritis are profillagrin, fillagrin and vimentin. Cells and tissues rich in those proteins have been used as substrate for the first laboratory assays for the detection of this class of autoantibodies. The discovery that the epitopes recognized by these autoantibodies are citrullin-bearing peptides permited the development of ELISA assays. The ELISA format allows better standardization and higher reproducibility for the tests, resulting in worldwide acceptance of these autoantibodies as the most specific and early serologic markers for the diagnosis of rheumatoid arthritis. There is controversy regarding the ability of these autoantibodies in predicting disease evolution. The role of antibodies to citrullinated peptides in the pathophysiology of rheumatoid arthritis is supported by their extreme specificity for the disease, by the finding of citrullinated proteins in inflamed synovia, by the intraarticular production of these autoantibodies and by the extreme affinity of citrullinated peptides for HLA-DRBI molecules bearing the shared epitope. These findings forecast the possibility of novel and exciting discoveries towards a better understanding of the pathophysiology of rheumatoid arthritis.
\end{abstract}

Keywords: rheumatoid arthritis, citrulline, anticitrullinated proteins antibodies, autoantibodies.

$\operatorname{antígenos}^{(2)}$. Contrariamente aos auto-anticorpos relacionados a doenças, estes são, em sua maioria, polirreativos, ocorrem em baixas concentrações e têm baixa afinidade. Por outro lado, os anticorpos ditos patológicos são, em geral, de classe IgG, apresentam altas afinidade, concentração sérica e especificidade ${ }^{(3)}$. A presença de altos níveis séricos deste último tipo de auto-anticorpos circulantes é uma das principais características das doenças auto-imunes ${ }^{(4)}$.

Recebido em 08/02/07. Aprovado, após revisão, em 10/04/07.

1. M.Sc., doutoranda em Ciências pela Disciplina de Reumatologia da Universidade Federal de São Paulo (Unifesp).

2. M.D., Ph.D., Professor Adjunto e livre-docente da Disciplina de Reumatologia da Universidade Federal de São Paulo (Unifesp).

Endereço para correspondência: Luís Eduardo C. Andrade, Rua Botucatu, 740, 3a andar, Disciplina de Reumatologia, Unifesp, CEP 04023-062, São Paulo, SP, Brasil, telefax: (55 11) 5579-6665, e-mail: luis@reumato.epm.br. 
A existência de uma variedade de auto-anticorpos no soro e no líquido sinovial de pacientes com artrite reumatóide (AR) tem sido descrita (Tabela 1). Nos últimos dez anos, uma série de trabalhos demonstrou que a família de auto-anticorpos mais específica para AR é a direcionada contra proteínas citrulinadas ${ }^{(5)}$. Esses anticorpos podem ser detectados em aproximadamente $80 \%$ dos soros de pacientes com AR com especificidade de $95 \%$ a $99 \%{ }^{(6)}$. Além disso, aparecem precocemente durante a evolução da enfermidade, portanto sua detecção apresenta-se bastante útil para auxiliar no diagnóstico da doença, especialmente em suas fases iniciais.

TABeLa 1

Desempenho Diagnóstico De Diferentes Sistemas DE AUTO-ANTICORPOS NA ARTRITE REUMATÓIDE

\begin{tabular}{lccc}
\hline Auto-anticorpo & Freqüência & Auto-anticorpo & Freqüência \\
\hline Fator reumatóide IgM & $75 \%$ & Anti-Sa & $40 \%$ \\
\hline Anti-RA-33 & $36 \%$ & Anti-BiP & $64 \%$ \\
\hline Anticalpastatina & $45 \%$ & Anti-GPI & $64 \%$ \\
Anticolágeno tipo II & $60 \%$ & Antiprofilagrina & $70-90 \%$ \\
\hline Antifibronectina & $14 \%$ & Antifilagrina & $35-60 \%$ \\
Anti-HGM-1 e anti-HGM-2 & $40 \%$ & Anti-CCP & $70-80 \%$ \\
\hline
\end{tabular}

$\mathrm{RA}-33$ = auto-antígeno de $33 \mathrm{kDa}$ associado à artrite reumatóide; $\mathrm{HGM}=$ high group mobility; $\mathrm{Sa}=$ auto-antígeno de placenta humana associado à artrite reumatóide; $\mathrm{BiP}=$ heavy chain binding protein $\mathrm{p} 68 ; \mathrm{GPI}=$ glucose-6-phosphatase isomerase; $\mathrm{CCP}=$ peptídeo citrulinado cíclico.

A citrulina não é um aminoácido-padrão, e sua presença em proteínas deve-se a uma modificação pós-traducional de proteínas contendo arginina catalisada pela enzima peptidilarginina deiminase (PADI). Essa afirmação é corroborada pela inexistência de tRNA para citrulina.

\section{PEPTIDILARGININA DEIMINASE}

A enzima PADI, descrita pela primeira vez em $1977^{(7)}$, catalisa a conversão de resíduos de arginina em resíduos de citrulina nas proteínas (Figura 1). Existem cinco subtipos de PADIs descritos, os quais serão detalhados a seguir.

PADIl é expressa principalmente na epiderme e no útero $^{(8,9)}$. Durante a diferenciação final dos queratinócitos, ocorre a citrulinação da queratina e da filagrina ${ }^{(10)}$. A citrulinação reduz a carga positiva da proteína, causando diminuição do potencial iônico e levando a um desdobramento parcial da proteína, podendo alterar as interações com outras moléculas ${ }^{(11)}$. Como conseqüência, acredita-se que a flexibilidade do citoesqueleto de queratina é reduzida, estimulando a cornificação da epiderme ${ }^{(12)}$.

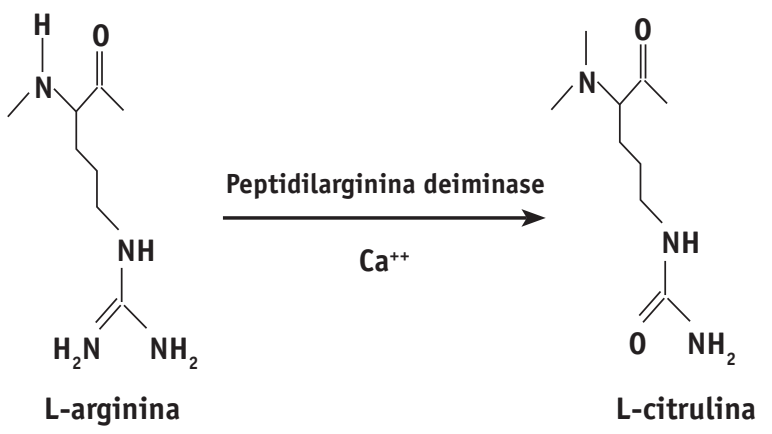

Figura 1 - Deiminação da arginina pela enzima peptidilarginina deiminase.

A PADI2 é amplamente expressa, sendo encontrada nos músculos, no cérebro, no baço e nas glândulas secretoras ${ }^{(8,13)}$. São conhecidos dois substratos naturais de PADI2, a mielina básica (sistema nervoso central) e a vimentina (músculos e macrófagos). Os níveis de PADI2 parecem ser regulados por hormônios. No útero, a PADI2 mostra-se relacionada com o nível de estrógeno, estando sua expressão três a quatro vezes mais elevada durante a fase estrogênica ${ }^{(9,14)}$. Outros tecidos não demonstraram expressão de PADI2 estrógeno-dependente ${ }^{(14)}$, sugerindo regulação hormonal tecido-específica.

A PADI3 apresenta co-expressão e co-localização com a proteína tricoialina da raiz capilar ${ }^{(15)}$. A tricoialina agrega os filamentos de queratina.

A PADI4, homóloga a PADI4 de ratos e camundon$\operatorname{gos}^{(16,17)}$, é expressa principalmente em granulócitos e monócitos, mas pode ser encontrada em uma variedade de tecidos ${ }^{(18)}$. É o único subtipo de PADI encontrado no núcleo celular ${ }^{(17)}$, sendo as histonas as proteínas nucleares descritas como seus alvos ${ }^{(17,19)}$.

Recentemente, um novo subtipo de PADI foi descrito, a PADI6. Ela foi encontrada no citoplasma de células germinativas ${ }^{(20)}$. Sua função e forma de regulação ainda não estão determinadas.

\section{AUTO-ANTICORPOS DIRECIONADOS A EPITOPOS CITRULINADOS}

\section{ANTIVIMENTINA E ANTI-SA}

Os auto-anticorpos contra antígeno Sa placentário foram descritos pela primeira vez na década passada. Os estudos sobre esse sistema auto-imune têm demonstrado alta especificidade em populações de pacientes com AR da 
Europa, da América e da Ásia ${ }^{(21)}$, de 92\% a 99\%, mas apresentam baixa sensibilidade, de $30 \%$ a $40 \%{ }^{(22,23)}$. Foi descrito originalmente como um antígeno de $50 \mathrm{kDa}$ a $55 \mathrm{kDa}$ da placenta e do fígado de humanos ${ }^{(22)}$, mas, posteriormente, foi encontrado em células endoteliais humanas, e várias bandas de pesos moleculares diferentes foram relatadas como sendo referentes ao antígeno $\mathrm{Sa}^{(24)}$. Esse antígeno pode ser detectado também no pannus reumatóide ${ }^{(22)}$.

Recentemente, o antígeno Sa foi identificado como sendo a proteína vimentina citrulinada ${ }^{(25)}$. A citrulinação de vimentina tem sido descrita em macrófagos humanos e de camundongos, células presentes abundantemente na sinóvia de $\mathrm{AR}^{(26,27)}$. Essa modificação pode estar envolvida na destruição do citoesqueleto de vimentina durante a morte dos macrófagos, quando a rede de filamentos de vimentina sofre colapso ${ }^{(28)}$.

Por ser Sa/vimentina um antígeno citrulinado, os anticorpos anti-Sa podem ser classificados como pertencentes à família de anticorpos antiproteínas citrulinadas.

\section{ANTICORPOS ANTIFATOR PERINUCLEAR (APF) E ANTIQUERATINA (AKA)}

O APF foi descrito em 1964 por Nienhuis e Mandema. Durante a investigação da ocorrência de fatores antinúcleo no soro de pacientes com lúpus eritematoso sistêmico, $\mathrm{AR}$, espondilite anquilosante e várias outras doenças pela técnica de imunofluorescência indireta (IFI) com células da mucosa bucal humana como substrato, um fator até então desconhecido foi encontrado. Foi observada uma fluorescência citoplasmática peculiar em células epiteliais de mucosa bucal de pessoas saudáveis, primeiramente incubadas com soro de pacientes reumatóides e, posteriormente, com conjugado antiimunoglobulina humana total, marcada com fluoresceína (Figura 2) ${ }^{(29)}$.

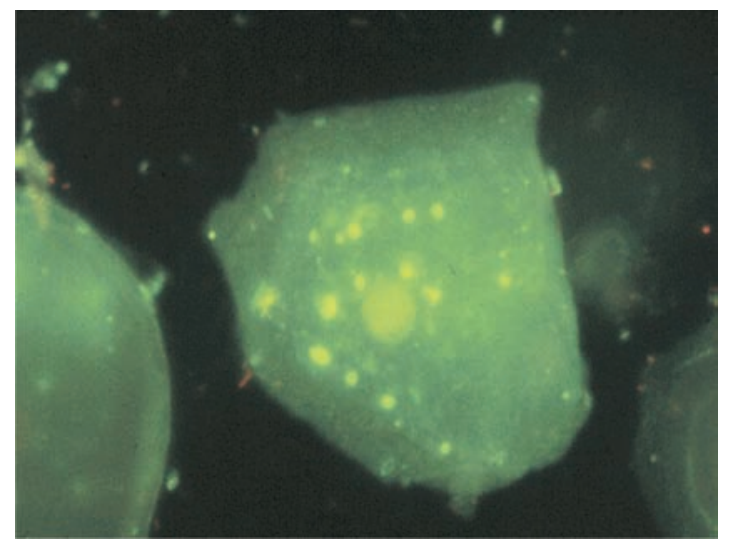

Figura 2 - Anticorpo APF. Imunofluorescência em queratinócitos orais humanos.
O padrão de fluorescência observado era caracterizado por grânulos citoplasmáticos fluorescentes, freqüentemente ao redor do núcleo (perinucleares). O antígeno reconhecido por esses auto-anticorpo foi denominado fator perinuclear, daí o termo anticorpo antifator perinuclear $(\mathrm{APF})^{(29)}$. O fenômeno de reconhecimento dos grânulos perinucleares pelo soro reumatóide era observado apenas em uma fração das células. Quase todos os soros contendo anticorpos antifator perinuclear, especialmente quando em títulos apreciáveis, foram encontrados em pacientes com AR. O APF foi inicialmente caracterizado como um anticorpo tipo gamaglobulina 7S, mas APFs das classes IgM e IgA também foram demonstrados, embora em menor freqüência.

Ao longo das últimas quatro décadas, vários estudos demonstraram que o auto-anticorpo APF apresenta sensibilidade de $49 \%$ a $91 \%$ e especificidade de $73 \%$ a $99 \%$ para a $\mathrm{AR}^{(5)}$. A ocorrência de APF independe do sexo e da idade do paciente. É independente da duração da doença, aparece precocemente e pode até mesmo preceder as manifestações clínicas da $\mathrm{AR}^{(30)}$.

As células da mucosa oral humana têm sido usadas como substrato-padrão para pesquisa do APF. Os anticorpos são reconhecidos pela presença de grânulos fluorescentes de 0,5 $\mu \mathrm{m}$ a $4 \mu \mathrm{m}$ de diâmetro, localizados no citoplasma ao redor do núcleo (em geral, três a quatro grânulos por célula). O soro é considerado positivo quando pelo menos cinco células são encontradas exibindo o característico padrão de fluorescência. Uma reação positiva com título de 1/80 é considerada relevante para o diagnóstico de $\mathrm{AR}^{(31)}$.

Os anticorpos antiqueratina (AKAs) foram descritos em 1979 (Figura 3). Esses anticorpos são direcionados contra estruturas na camada córnea do esôfago de ratos. AKA pode ser detectado por meio de imunofluorescência indireta em $36 \%$ a $59 \%$ dos soros de AR com especificidade de $88 \%$ a $99 \%$. Nos estudos iniciais, o antígeno-alvo foi erroneamente identificado como queratina. Estudos imunológicos e bioquímicos posteriores demonstraram que tanto o APF quanto o AKA reconhecem a proteína filagrina e seu precursor, a profilagrina ${ }^{(30)}$. A filagrina é uma proteína que se agrega a filamentos de queratina, formando uma macrofibrila densa que protege a queratina de clivagem proteolítica $^{(32,33)}$.

Hoet et al. ${ }^{(34)}$, em 1991, descreveram a co-localização do APF e do AKA com anticorpos monoclonais específicos para a proteína (pro)filagrina nas células da mucosa bucal e no estrato córneo de esôfago de rato, respectivamente. Esse achado foi confirmado e estendido para a caracterização imunológica e bioquímica de (pro)filagrina como 


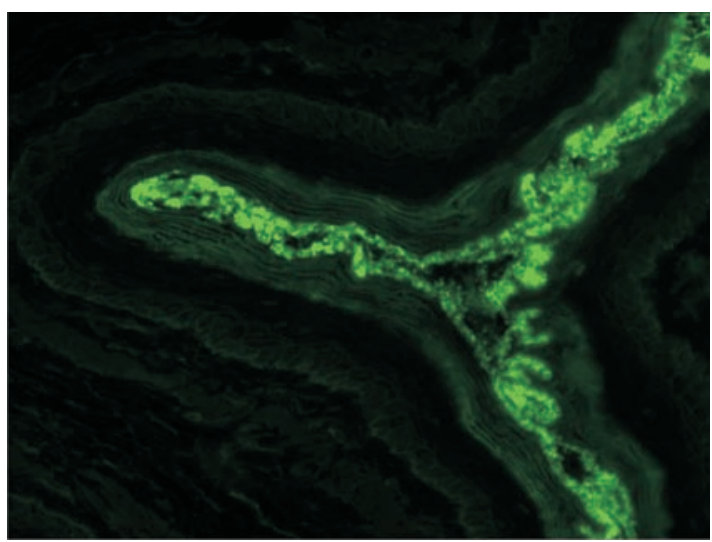

Figura 3 - Anticorpo antiqueratina. Imunofluorescência em esôfago de rato.

auto-antígeno no teste do APF e no AKA. Portanto, esses anticorpos seriam mais corretamente chamados de anticorpos antifilagrina (AFA) ${ }^{(33,35)}$.

Por mais de três décadas, a natureza dos antígenos reconhecidos pelos anticorpos APF e AKA permaneceu desconhecida. Uma das características da célula escamosa da mucosa oral é a presença de grânulos perinucleares, denominados grânulos ceratoialinos. Da mesma forma, o estrato córneo do esôfago de rato é extremamente rico em filagrina. A profilagrina e a filagrina são os principais componentes dos grânulos ceratoialinos humanos. A profilagrina é um precursor insolúvel da filagrina, rica em arginina, constituindo-se em 10 a 12 repetições seqüenciais de arranjos de filagrina, separadas por uma pequena seqüência de um heptapeptídeo ligador. $\mathrm{O}$ precursor é acumulado na forma não funcional e altamente fosforilada, na camada córnea do epitélio queratinizado, antes de ser desfosforilado e clivado por excisão da seqüência ligadora para liberar a filagrina funcional ${ }^{(31)}$. A agregação da filagrina dentro do grânulo e posterior processamento pode depender da concentração de cálcio, já que a região aminoterminal mostra grande homologia com a família S-100 das proteínas ligadoras de cálcio.

Essas observações levaram, naturalmente, muitos pesquisadores a acreditarem que o auto-antígeno reconhecido pelos anticorpos APF seria a filagrina e seu precursor, a profilagrina $^{(30)}$. Entretanto, em 1989, o grupo liderado por van Venrooij ${ }^{(36)}$ logrou demonstrar que os epitopos reconhecidos pelos anticorpos APF dirigiam-se exclusivamente contra peptídeos contendo pelo menos uma molécula de citrulina. Essa foi uma descoberta fundamental e possibilitou a migração dos ensaios imunológicos para a plataforma de enzimaimunoensaio em fase sólida (ELISA) em que o substrato antigênico é representado por coleções de peptídeos citrulinados pré-adsorvidos a placas de poliestireno.

\section{ANTICORPOS CONTRA PEPTÍDEOS CITRULINADOS CÍCLICOS (ANTI-CCP)}

Uma vez demonstrado que o auto-epitopo relevante da filagrina e profilagrina era representado por peptídeos com resíduos de citrulina, foram desenvolvidos testes sorológicos por ELISA para a detecção de anticorpos antipeptídeo citrulinado. Em uma segunda etapa, esses testes foram otimizados mediante o uso de peptídeos citrulinados cíclicos (CCP), uma vez que a forma cíclica do peptídeo favorece o seu reconhecimento pelos anticorpos. Os testes para detecção de anticorpos anti-CCP têm apresentado excelente desempenho diagnóstico, e o formato de ELISA permite a padronização comercial do método ${ }^{(36)}$. Esse teste possui excelente especificidade, cerca de $96 \%$, e sua sensibilidade é de $60 \%$ a $75 \%$ para o diagnóstico da AR, podendo ser utilizado em pacientes com doença precoce ${ }^{(35,36)}$.

A sensibilidade desse teste é limitada, pois o peptídeo utilizado é derivado da filagrina e, como esta não é expressa em sinóvia, não é provável que corresponda ao antígeno natural dos auto-anticorpos antiproteína citrulinada. Por esse motivo, uma segunda geração de testes anti-CCP foi desenvolvida (anti-CCP2) a partir de uma biblioteca de peptídeos citrulinados testados com soros de $\mathrm{AR}^{(37,38)}$. Lançando mão da tecnologia de bibliotecas de phage display, foram selecionados os peptídeos citrulinados que melhor discriminassem a reatividade de soros de pacientes reumatóides. Dessas bibliotecas, novos peptídeos citrulinados, homólogos à filagrina ou a outras proteínas citrulinadas conhecidas, foram obtidos e incorporados ao teste, atribuindo-lhe sensibilidade de $82 \%$ e especificidade de $98,5 \%{ }^{(6)}$.

A AR é diagnosticada, primariamente, com base em suas manifestações clínicas, mas tem, tradicionalmente, seu suporte sorológico dado pela determinação do fator reumatóide (FR) IgM. Porém, esse auto-anticorpo ocorre em pessoas com várias doenças inflamatórias, algumas doenças infecciosas e neoplásicas e, até mesmo, em pessoas hígidas, especialmente naquelas com idade elevada. O sistema de auto-anticorpos contra proteínas citrulinadas mostrou-se mais específico do que o FR e, portanto, de maior utilidade para o diagnóstico da $\mathrm{AR}$, principalmente em suas fases iniciais ${ }^{(39)}$.

O valor do sistema de auto-anticorpos antifilagrina está bem estabelecido para o diagnóstico da $\mathrm{AR}$, porém o mesmo não se pode dizer quanto à sua capacidade em predizer a gravidade da enfermidade. Os estudos sobre correlação entre esses auto-anticorpos e a gravidade da AR apresentam considerável controvérsia na literatura. A 
maioria dos trabalhos aponta claramente que pacientes com artrite de início recente terão pior prognóstico articular se apresentarem anticorpos antifilagrina (APF, AKA ou anti-CCP $)^{(40-43)}$. Por outro lado, entre pacientes com AR bem estabelecida, a presença desses auto-anticorpos não parece sinalizar doença mais grave ${ }^{(44-46)}$. Portanto os anticorpos antifilagrina, provavelmente, indicam prognóstico em pacientes com doença recente em função de ser um marcador diagnóstico sorológico precoce para $\mathrm{AR}$, assim discriminando os verdadeiros casos de AR no universo de casos de poliartrite de início recente.

Santos $e t ~ a l .{ }^{(47)}$ realizaram um estudo com mais de 170 pacientes brasileiros com AR, com três meses a 30 anos de doença, pesquisando a influência dos anticorpos APF e AKA na progressão da AR. Diversos parâmetros foram utilizados para avaliação desses pacientes: índice combinado para avaliação de atividade de doença, avaliação funcional, realizada por meio do HAQ e da classificação funcional de Steinbrocker e a avaliação radiográfica pelo método de Sharp. O APF e o AKA, a despeito da reconhecida importância no diagnóstico de $\mathrm{AR}$, mostraram-se inadequados para definir um grupo de pacientes com forma mais agressiva da doença. Em outro estudo do nosso grupo, 71 pacientes com AR bem definida, com dois ou mais anos de evolução, foram selecionados e acompanhados durante oito anos para investigação da associação dos auto-anticorpos com a gravidade da AR. Nessa avaliação, o delta Sharp, ou seja, a diferença no escore de Sharp entre o oitavo e o primeiro ano de acompanhamento, foi o parâmetro utilizado para definir a evolução das erosões ósseas. Os resultados indicam que não foi encontrada correlação entre os anticorpos do sistema da filagrina-citrulina e a gravidade da $\mathrm{AR}^{(44)}$. Nesse estudo em particular, não havia pacientes com doença com menos de dois anos de evolução, portanto o diagnóstico de AR estava bem consolidado.

\section{O SIGNIFICADO FISIOPATOLÓGICO DOS ANTICORPOS ANTIPROTEÍNAS CITRULI- NADAS NA ARTRITE REUMATÓIDE}

Os anticorpos antiproteínas citrulinadas são produzidos na sinóvia reumatóide ${ }^{(48,49)}$, sugerindo a presença de proteínas citrulinadas no local. Macrófagos e granulócitos expressam PADI2, enzima que está inativa em condições fisiológicas normais, devido à baixa concentração de cálcio intracelular. Durante a morte dessas células, os processos homeostáticos falham e íons de cálcio entram nas células, ativando a PADI. Proteínas intracelulares como vimen- tina e histona são citrulinadas e podem ganhar o meio extracelular. Além disso, a própria enzima PADI pode extravasar e citrulinar proteínas extracelulares, como a fibrina. Essas proteínas citrulinadas expostas ao sistema imunológico sob condições adjuvantes, como no contexto da sinóvia inflamada, podem levar a uma resposta imunológica específica.

Aparentemente, vários fenômenos de modificações póstraducionais têm papel fundamental associado à quebra da imunotolerância e na ativação de reatividades autoimunes ${ }^{(50)}$. Modificações em proteínas próprias podem aflorar epitopos crípticos e/ou criar novos epitopos aos quais não exista uma tolerância preestabelecida, podendo suscitar resposta auto-imune em indivíduos suscetíveis. Uma dessas modificações que criam novos epitopos pode ser a citrulinação ${ }^{(39)}$. Embora a citrulinação seja um fenômeno normal e prevalente em indivíduos saudáveis, desvios na intensidade, localização e persistência de citrulinação poderiam acarretar reações imunológicas anômalas conforme o ambiente adjuvante vigente e a constituição imunogenética individual.

Estudos de imuno-histoquímica demonstraram a presença de anticorpos anticitrulina altamente específicos em sinóvia de pacientes com $\mathrm{AR}^{(48,49,51)}$. Masson-Bessière et $a l^{(48)}$ descobriram que títulos de anticorpos IgG dirigidos para a filagrina citrulinada em líquido sinovial e em extratos de tecido sinovial de pacientes com artrite reumatóide são 1,4 e 7,5 vezes mais elevadas, respectivamente, do que no soro do mesmo paciente. Ademais, demonstrou-se que as células B do fluido sinovial de pacientes com artrite reumatóide produzem espontaneamente anti-CCP(50).

Uma vez caracterizadas a alta especificidade dos anticorpos antipeptídeos citrulinados na AR e a produção de anticorpos antipeptídeos citrulinados na própria sinóvia, seria imperativo demonstrar a presença de epitopos citrulinados nesse tecido. Fazendo uma pesquisa para detecção de proteínas citrulinadas na sinóvia, o alvo mais óbvio do auto-anticorpo em questão seria a proteína filagrina em si, o antígeno reconhecido nos testes de APF e AKA. No entanto, não foi possível detectar filagrina nem profilagrina em tecido sinovial normal ou reumatóide ${ }^{(52,53)}$. Por outro lado, os pesquisadores conseguiram detectar a presença de outras proteínas citrulinadas no tecido sinovial inflamado, e sua caracterização bioquímica levou à identificação de cadeia $\alpha$ e $\beta$ de fibrina ${ }^{(50)}$. Outros pesquisadores demonstraram também a presença de vimentina citrulinada, possivelmente proveniente de macrófagos locais ${ }^{(28)}$. 
A demonstração de proteínas citrulinadas na sinóvia e de produção local de anticorpos contra epitopos citrulinados parece fechar o elo fisiopatológico da artrite reumatóide. Porém Vossenaar et al., em 2004 $4^{(51)}$, constataram que a presença de proteína citrulinada não é uma característica exclusiva do tecido sinovial reumatóide, sendo encontrada também em vários outros processos inflamatórios articulares. Portanto, a razão pela qual apenas na artrite reumatóide ocorre a resposta imunológica contra epitopos citrulinados permanece desconhecida.

A distribuição em subclasses do anticorpo antiproteína citrulinada (predominantemente IgGl) é indicativa de uma produção de anticorpo dependente de célula T. Essa observação coaduna-se com a bem conhecida associação entre artrite reumatóide e determinados alelos do antígeno leucocitário humano (HLA). De fato, há mais de 25 anos sabe-se que certos haplótipos do HLA conferem predisposição genética à $\mathrm{AR}^{(54)}$. $\mathrm{O}$ refinamento progressivo dessas observações definiu que os alelos envolvidos na predisposição à artrite reumatóide comungam um domínio molecular na terceira região de hipervariabilidade da cadeia $\beta$ do HLA-DR (Quadro 1). Os aminoácidos 67 a 74 [LLEQK(R)RRAA], exclusivamente presentes nos alelos associados à artrite reumatóide, compõem o denominado epitopo compartilhado. O significado fisiopatológico dessa associação não está definido.

\section{QUADro 1}

Alelos do HLA-DRBI Que Possuem epitopo COMPARTILHADO E ESTÃO RELACIONADOS COM A PREDISPOSIÇÃO À ARTRITE REUMATÓIDE

\begin{tabular}{lll}
\hline DRB1 *0101 & DRB1 *0404 & DRB1 *0410 \\
DRB1 *0102 & DRB1 *0405 & DRB1 *1001 \\
DRB1 *0401 & DRB1 *0408 & DRB1 *1402
\end{tabular}

\section{REFERÊNCIAS}

1. Avrameas S: Natural autoantibodies: from 'horror autotoxicus' to 'gnothi seauton'. Immunol Today 12(5):154-9, 1991.

2. Guilbert B, Dighiero G, Avrameas S: Naturally occurring antibodies against nine common antigens in human sera. I. Detection, isolation and characterization. J Immunol 128(6):2779-87, 1982 .

3. Stollar BD: Autoantibodies and autoantigens: a conserved system that may shape a primary immunoglobulin gene pool. Mol Immunol 28(12):1399-412, 1991.

4. Tan EM: Autoantibodies in pathology and cell biology. Cell 29;67(5):841-2, 1991.
Recentemente, foi demonstrado que peptídeos citrulinados podem se ligar com maior afinidade a moléculas HLA contendo o epitopo compartilhado do que os peptídeos correspondentes não-citrulinados ${ }^{(55)}$. Esse achado é extremamente interessante, uma vez que poderia representar a resposta para as perguntas não respondidas dos parágrafos anteriores, ou seja, a resposta imunológica a peptídeos citrulinados restrita à $\mathrm{AR}$ e a associação específica dessa enfermidade com os alelos HLA contendo o epitopo compartilhado. Esse raciocínio é corroborado pelos recentes achados de forte correlação entre alelos do HLA com o epitopo compartilhado e a presença do anticorpo anti-CCP em pacientes com $\mathrm{AR}^{(54)}$.

\section{CONCLUSÃO}

Os últimos dez anos presenciaram descobertas excitantes sobre os aspectos imunológicos da artrite reumatóide. Os auto-anticorpos AR-específicos APF e AKA, conhecidos há algumas décadas, tiveram sua natureza imunológica definida e passaram a ter ampla aceitação como os marcadores mais específicos e precoces dessa enfermidade. Em verdade, pode-se considerar que houve uma mudança no paradigma do diagnóstico sorológico da AR. Em paralelo, os peptídeos citrulinados passaram a ocupar uma posição de destaque na investigação da fisiopatologia da artrite reumatóide. Finalmente, parece haver uma convergência entre os tradicionais e intrigantes dados imunogenéticos da $\mathrm{AR}$ e os recentes achados relativos à posição privilegiada dos peptídeos citrulinados na resposta imunológica dessa enfermidade. Em seu todo, o momento atual é estimulante e acena com a possibilidade de reais avanços no entendimento e manejo dessa importante doença auto-imune.

Declaramos a inexistência de conflitos de interesse.
5. van Boekel MA, Vossenaar ER, van den Hoogen FH, van Venrooij WJ: Autoantibody systems in rheumatoid arthritis: specificity, sensitivity and diagnostic value. Arthritis Res 4(2):87-93, 2002.

6. van Venrooij WJ, Hazes JM, Visser H: Anticitrullinated protein/ peptide antibody and its role in the diagnosis and prognosis of early rheumatoid arthritis. Neth J Med 60:383-8, 2002.

7. Rogers GE, Harding HW, Llewellyn-Smith IJ: The origin of citrulline-containing proteins in the hair follicle and the chemical nature of trichohyalin, an intracellular precursor. Biochim Biophys Acta 25;495(1):159-75, 1977.

8. Guerrin M, Ishigami A, Mechin MC, et al.: cDNA cloning, gene organization and expression analysis of human peptidylarginine deiminase type I. Biochem J 15;370:167-74, 2003. 
9. Tsuchida $\mathrm{M}$, Takahara $\mathrm{H}$, Minami $\mathrm{N}$, et al.: cDNA nucleotide sequence and primary structure of mouse uterine peptidylarginine deiminase. Detection of a 3'-untranslated nucleotide sequence common to the mRNA of transiently expressed genes and rapid turnover of this enzyme's mRNA in the estrous cycle. Eur J Biochem 1;215(3):677-85, 1993.

10. Senshu T, Kan S, Ogawa H, Manabe M, Asaga H: Preferential deimination of keratin $\mathrm{Kl}$ and filaggrin during the terminal differentiation of human epidermis. Biochem Biophys Res Commun 23;225(3):712-9, 1996.

11. Tarcsa E, Marekov LN, Mei G, Melino G, Lee SC, Steinert PM: Protein unfolding by peptidylarginine deiminase. Substrate specificity and structural relationships of the natural substrates trichohyalin and filaggrin. J Biol Chem 29;271(48):30709-16, 1996.

12. Ishida-Yamamoto A, Senshu T, Eady RA, et al.: Sequential reorganization of cornified cell keratin filaments involving filaggrin-mediated compaction and keratin 1 deimination. J Invest Dermatol 118(2):282-7, 2002.

13. Watanabe K, Senshu T: Isolation and characterization of cDNA clones encoding rat skeletal mucle peptidylarginine deiminase. J Biol Chem 264: 15255-60, 1989.

14. Takahara H, Tsuchida M, Kusubata M, Akutsu K, Tagami S, Sugawara K: Peptidylarginine deiminase of the mouse. Distribution, properties, and immunocytochemical localization. J Biol Chem 5;264(22):13361-8, 1989.

15. Rogers G, Winter B, McLaughlan C, Powell B, Nesci T: Peptidylarginine deiminase of the hair follicle: characterization, localization, and function in keratinizing tissues. J Invest Dermatol 108(5):700-7, 1997.

16. Asaga H, Nakashima $\mathrm{K}$, Senshu T, Ishigami A, Yamada M: Immunocytochemical localization of peptidylarginine deiminase in human eosinophils and neutrophils. J Leukoc Biol 70(1): 46-51, 2001.

17. Nakashima K, Hagiwara T, Yamada M: Nuclear localization of peptidylarginine deiminase $\mathrm{V}$ and histone deimination in granulocytes. J Biol Chem 20;277(51):49562-8, 2002.

18. Yamakoshi A, Ono H, Nishijyo $T$, Shiraiwa $M$, Takahara $H$ : Cloning of cDNA encoding a novel isoform (type IV) of peptidylarginine deiminase from rat epidermis. Biochim Biophys Acta 28;1386(1):227-32, 1998 .

19. Hagiwara T, Nakashima K, Hirano H, Senshu T, Yamada M: Deimination of arginine residues in nucleophosmin/B23 and histones in HL-60 granulocytes. Biochem Biophys Res Commun 25;290(3):979-83, 2002.

20. Wright PW, Bolling LC, Calvert ME, et al.: ePADI, an oocyte and early embryo-abundant peptidylarginine deiminase-like protein that localizes to egg cytoplasmic sheets. Dev Biol 1;256(1): 73-88, 2003

21. Menard HA, Lapointe E, Rochdi MD, Zhou ZJ: Insights into rheumatoid arthritis derived from the Sa immune system. Arthritis Res 2(6):429-32, 2000.

22. Despres N, Boire G, Lopez-Longo FJ, Menard HA: The Sa system: a novel antigen-antibody system specific for rheumatoid arthritis. J Rheumatol 21(6):1027-33, 1994.

23. Hueber W, Hassfeld W, Smolen JS, Steiner G: Sensitivity and specificity of anti-Sa autoantibodies for rheumatoid arthritis. Rheumatology (Oxford) 38(2):155-9, 1999.
24. Escalona M, Lopez-Longo FJ, Gonzalez CM, et al.: Anti-Sa sera from patients with rheumatoid arthritis contain at least 2 different subpopulations of anti-Sa antibodies. J Rheumatol 29(10): 2053-60, 2002.

25. Kraan MC, Reece RJ, Barg EC, et al.: Modulation of inflammation and metalloproteinase expression in synovial tissue by leflunomide and methotrexate in patients with active rheumatoid arthritis. Findings in a prospective, randomized, double-blind, parallel-design clinical trial in thirty-nine patients at two centers. Arthritis Rheum 43(8):1820-30, 2000.

26. Asaga $H$, Yamada M, Senshu T: Selective deimination of vimentin in calcium ionophore-induced apoptosis of mouse peritoneal macrophages. Biochem Biophys Res Commun 24;243(3):641-6, 1998.

27. Vossenaar ER, Radstake TR, van der Heijden A, et al.: Expression and activity of citrullinating peptidylarginine deiminase enzymes in monocytes and macrophages. Ann Rheum Dis 63(4):373-81, 2004.

28. Vossenaar ER, Despres N, Lapointe E, et al.: Rheumatoid arthritis specific anti-Sa antibodies target citrullinated vimentin. Arthritis Res Ther 6(2):R142-50, 2004.

29. Nienhuis RL \& Mandema E: A new serum factor in patients with rheumatoid arthritis; the antiperinuclear factor. Ann Rheum Dis 23:302-305, 1964.

30. Sebbag M, Simon M, Vicent C, et al.: The antiperinuclear factor and so-called antikeratin antibodies are the same rheumatoid arthritis-specific autoantibodies. J Clin Invest 95:2672-79, 1995.

31. Youinou P \& Serre G: The antiprofilagrina factor and antikeratin antibody systems. Int Arch Allergy Immunol 107: 508-518, 1995

32. Mack JW, Steven AC, Steinert PM: The mechanism of interaction of filaggrin with intermediate filaments. The ionic zipper hypothesis. J Mol Biol 5;232(1):50-66, 1993.

33. Manabe M, Sanchez M, Sun TT, Dale BA: Interaction of filaggrin with keratin filaments during advanced stages of normal human epidermal differentiation and in ichthyosis vulgaris. Differentiation 48(1):43-50, 1991.

34. Hoet RM, Boerbooms AM, Arends M, Ruiter DJ, van Venrooij WJ: Antiperinuclear factor, a marker autoantibody for rheumatoid arthritis: colocalisation of the perinuclear factor and profilaggrin. Ann Rheum Dis 50(9): 611-8, 1991.

35. Schellekens GA, Visser H, de Jong BA, et al.: The diagnostic properties of rheumatoid arthritis antibodies recognizing a cyclic citrullinated peptide. Arthritis Rheum 43(1):155-63, 2000.

36. Schellekens GA, de Jong BA, van den Hoogen FH, van de Putte LB, van Venrooij WJ: Citrulline is an essential constituent of antigenic determinants recognized by rheumatoid arthritisspecific autoantibodies. J Clin Invest 101(1):273-81, 1998.

37. Hiemstra HS, Benckhuijsen WE, Amons R, Rapp W, Drijfhout JW: A new hybrid resin for stepwise screening of peptide libraries combined with single bead Edman sequencing. J Pept Sci 4(4):282-8, 1998.

38. de Koster HS, Amons R, Benckhuijsen WE, Feijlbrief M, Schellekens GA, Drijfhout JW: The use of dedicated peptide libraries permits the discovery of high affinity binding peptides. J Immunol Methods 16;187(1):179-88, 1995. 
39. van Venrooij WJ \& Pruijn GJM: Citrullination: a small change for a protein with great consequences for rheumatoid arthritis. Arthritis Res 2:249-51, 2000.

40. Kroot EJ, de Jong BA, van Leeuwen MA, et al.: The prognostic value of anti-cyclic citrullinated peptide antibody in patients with recent-onset rheumatoid arthritis. Arthritis Rheum 43(8):1831-5, 2000.

41. Forslin K, Vincent C, Serre G, Svensson B: Antifilaggrin antibodies in early rheumatoid arthritis may predict radiological progression. Scand J Rheumatol 30(4):221-4, 2001.

42. Meyer O, Labarre C, Dougados M, et al.: Anticitrullinated protein/peptide antibody assays in early rheumatoid arthritis for predicting five year radiographic damage. Ann Rheum Dis 62(2):120-62, 2003.

43. Visser H, le Cessie S, Vos K, Breedveld FC, Hazes JM: How to diagnose rheumatoid arthritis early: a prediction model for persistent (erosive) arthritis. Arthritis Rheum 46(2):357-65, 2002.

44. Nieto CAN, Santos WS, Keusseyan SP, Caldan WCI, Fernandes ARC, Andrade LEC: The role of rheumatoid factor and antibodies to citrullinated peptides in predicting disease severity in well established rheumatoid arthritis. Scand J Rheumatol submitted.

45. Paimela L, Palosuo T, Aho K, et al.: Association of autoantibodies to filaggrin with an active disease in early rheumatoid arthritis. Ann Rheum Dis 60(1):32-5, 2001.

46. Bas S, Perneger TV, Mikhnevitch E, et al.: Association of rheumatoid factors and anti-filaggrin antibodies with severity of erosions in rheumatoid arthritis. Rheumatology (Oxford) 39(10):1082-8, 2000 .

47. Santos WS, Fernandes ARC, Silva NP, Atra E, Andrade LEC: Significado clínico do fator antiperinuclear e anticorpo antiestrato córneo na artrite reumatóide* Parte 2. Rev Bras Reumatol 37(6):309-16, 1997.

48. Masson-Bessiere C, Sebbag M, Durieux JJ, et al.: In the rheumatoid pannus, anti-filaggrin autoantibodies are produced by local plasma cells and constitute a higher proportion of IgG than in synovial fluid and serum. Clin Exp Immunol 119(3): 544-52, 2000.

49. Reparon-Schuijt CC, van Esch WJ, van Kooten C, et al.: Secretion of anti-citrulline-containing peptide antibody by B lymphocytes in rheumatoid arthritis. Arthritis Rheum 44(1):41-7, 2001.

50. Union A, Meheus L, Humbel RL, et al.: Identification of citrullinated rheumatoid arthritis-specific epitopes in natural filaggrin relevant for antifilaggrin autoantibody detection by line immunoassay. Arthritis Rheum 46(5):1185-95, 2002

51. Vossenaar ER, Smeets TJ, Kraan MC, et al.: The presence of citrullinated proteins is not specific for rheumatoid synovial tissue. Arthritis Rheum 50(11):3485-94, 2004.

52. Masson-Bessiere C, Sebbag M, Girbal-Neuhauser E, et al.: The major synovial targets of the rheumatoid arthritis-specific antifilaggrin autoantibodies are deiminated forms of the alphaand beta-chains of fibrin. J Immunol 166(6):4177-84, 2001.

53. Baeten D, Peene I, Union A, et al.: Specific presence of intracellular citrullinated proteins in rheumatoid arthritis synovium: relevance to antifilaggrin autoantibodies. Arthritis Rheum 44(10):2255-62, 2001.

54. Vossenaar ER \& van Venrooij WJ: Citrullinated proteins: sparks that may ignite the fire in rheumatoid arthritis. Arthritis Res Ther 6:107-11, 2004

55. Hill JA, Southwood S, Sette A, Jevnikar AM, Bell DA, Cairns E: Cutting edge: the conversion of arginine to citrulline allows for a high-affinity peptide interaction with the rheumatoid arthritisassociated HLA-DRBI * $0401 \mathrm{MHC}$ class II molecule. J Immunol 171:538-41, 2003. 